UDK 528.14

\title{
CRITERION FOR COMPARING THE VARIANCE COMPONENT ESTIMATION METHODS USED FOR ADJUSTING HORIZONTAL CONTROL NETWORKS
}

\author{
Erol Yavuz ${ }^{1}$, Orhan Baykal ${ }^{2}$ \\ ${ }^{1}$ Yildiz Teknik Universitesi, Meslek Yüksekokulu, Harita Programi \\ Buyukdere Cad. No: 69 Maslak - Istanbul, \\ e-mail: erolyavuz1962@hotmail.com \\ ${ }^{2}$ Istanbul Teknik Universitesi, Insaat fakultesi \\ Buyukdere Cad. Maslak - Istanbul, \\ e-mail: obaykal@srv.ins.itu.edu.tr
}

Received 0604 2005, accepted 14122005

\begin{abstract}
Determination of which stochastic model taken in hand for this study is suitable under conditions, when comparing stochastic models, used for adjusting horizontal control networks, is the aim of this study. Some well-known variance component estimation methods like Conventional, Helmert, MINQUE, AUE, and Förstner, which have been developed to determine the stochastic model, necessary to be formed in a real way for adjusting geodetic nets, have been compared. For comparing the models mentioned above, concrete deciding criteria, using statistical tests, have been defined and the determination of which model is superior has been studied. For comparison of the models, numerical experiment using data, which belong to the part of Istanbul Metropolitan Triangulation Network (Asiatic side of Istanbul), has been performed.
\end{abstract}

Keywords: horizontal control network, variance component estimation method, adjustment of geodetic net.

\section{Introduction}

In order to compare the stochastic models used for adjustment of horizontal control networks, which require the highest accuracy, firstly, concrete comparing criteria must be defined by statistical tests.

If the hypotheses given below are valid, reliable results can be got by using the comparison criteria explained later:

1. ,all gross and systematic errors have been eliminated before adjustment",

2 . „there is not a functional model error".

\section{Stochastic models used in horizontal control networks}

Some well-known stochastic models have been taken for this study. These are

\section{a. Estimation of variance components using conventional stochastic model (Model 1)}

The standard deviations of a net directions, which are evaluated as groups, can be obtained either from Ferrero equation

$$
\sigma_{0}=\sqrt{\frac{[\mathrm{ww}]}{6 n}}
$$

or from station adjustment

$$
\begin{aligned}
& \sigma_{d}=\sqrt{\frac{[v v]}{(n-1)(s-1)}}, \\
& \sigma_{0}=\frac{\sigma_{d}}{\sqrt{n}} .
\end{aligned}
$$

A priori variances of the distance measurements can be obtained using either equation (2.4), which is given by the instrument manufacturer,

$$
\sigma_{s}^{2}=a^{2}+b^{2} \times S^{2}
$$

or the equations

$$
\begin{aligned}
& \sigma_{0}=\sqrt{\frac{[g g]}{2 n}}, \\
& \sigma_{s}=\frac{\sigma_{0}}{\sqrt{2}} .
\end{aligned}
$$

After computing variances of distances and directions, assuming that a priori variance, determined for a group of directions, is a priori variance $\left(\sigma_{0}^{2}\right)$ for unit of the weight measurement, and weights of the other directions groups and weights of distances of the net 
could be obtained from this a priori variance for unit of the weight $\left(P_{i}=1\right)$. So weights of other direction groups

$$
P_{j}=\frac{\sigma_{0}^{2}}{\sigma_{j}^{2}},
$$

and weights of distances

$$
P_{s}=\frac{\sigma_{0}^{2}}{\sigma_{s}^{2}} .
$$

Because this model, used for the adjustment of horizontal control networks, does not reflect exactly the net geometry and the real conditions during surveying, adjustment results and their precision, determined by this model, are questionable.

\section{b. Estimation of variance components by Helmert method (Model 2)}

The variance components are estimated iteratively by Helmert method. In the method, the determination of the variance components can be summarised in the following steps.

Step 1. Observations are grouped as $m$ numbered according to the measurement methods and the weight matrix is estimated for each group before adjustment. Identity matrix can be taken as the weight matrix of the groups at the beginning of the iteration (Sahin, 1992; Yavuz, 2000):

$$
\underline{P}_{1}=\underline{P}_{2}=\ldots \underline{P}_{m}=1 .
$$

Step 2. In this step, global matrix $\underline{N}$ and normal matrix $\underline{N}_{1}, \underline{N}_{2}, \ldots, \underline{N}_{m}$ of each group are formed by the initial weights:

$$
\begin{aligned}
& \underline{N}_{k}=\underline{A}_{k}^{T} \underline{P}_{k} \underline{A}_{k} \quad(k=1,, \ldots, m), \\
& \underline{N}=\underline{A}^{T} \underline{P A}=\underline{N}_{1}+\underline{N}_{2}+\ldots+\underline{N}_{m},
\end{aligned}
$$

where

$\underline{A}_{k}:$ coefficient matrix of the group k-th,

A coefficient matrix of all observations.

Step 3. In this step, the unknown parameters and the observation residuals are determined as

$$
\begin{aligned}
& \underline{x}=\underline{N}^{-1} \underline{A}^{T} \underline{P b}, \\
& \underline{V}_{k}=\underline{A}_{k} \underline{x}^{-\underline{b}_{k}} \quad(k=1, \ldots, m)
\end{aligned}
$$

where

$$
\begin{aligned}
& \underline{x}: \text { unknown parameters, } \\
& \underline{b}: \text { observation vectors of all groups, } \\
& \underline{b}_{k}: \text { measurements vector of group k-th, } \\
& \underline{V}_{k}: \text { residual vector of group k-th. }
\end{aligned}
$$

Step 4. After these three steps, Helmert equation is formed as

$$
\left[\begin{array}{cccc}
h_{11} & h_{12} & \ldots & h_{1 m} \\
h_{21} & h_{22} & \ldots & h_{2 m} \\
\cdot & \cdot & \ldots & \cdot \\
h_{m 1} & h_{m 2} & \ldots & h_{m m}
\end{array}\right]\left[\begin{array}{c}
-2 \\
\sigma_{1} \\
\bar{\sigma}_{2} \\
\bar{\sigma}_{m}
\end{array}\right]=\left[\begin{array}{c}
c_{1} \\
c_{2} \\
\cdot \\
c_{m}
\end{array}\right],
$$

where

$$
\begin{aligned}
\underline{c}_{k} & =\underline{V}_{k}^{T} \underline{P}_{k} \underline{A}_{k}, \\
\underline{h}_{k k} & =n_{k}-2 \operatorname{Tr}\left(\underline{N}^{-1} \underline{N}_{k}\right)+\operatorname{Tr}\left(\underline{N}^{-1} \underline{N}_{k} \underline{N}^{-1} \underline{N}_{k}\right), \\
\underline{h}_{k j} & =\operatorname{Tr}\left(\underline{N}^{-1} \underline{N}_{j} \underline{N}^{-1} \underline{N}_{k}\right)(\text { for } k \neq j),
\end{aligned}
$$

where $\bar{\sigma}_{k}^{2}(k=1,2, \ldots, m)$ variance of group $k$-th.

Step 5. In this step, Helmert equation (2.13) is solved and the variance of each group is obtained. Then the weights of the observation groups are computed by the equation

$$
P_{k+1}=\frac{P_{k}}{\bar{\sigma}_{k}^{2}} .
$$

If $\bar{\sigma}_{k}^{2}$ is not equal to 1 for all $k=1,2, \ldots, m$ the procedure returns to step 2 . When $\bar{\sigma}_{k}^{2}=1$ for all observation groups, iteration is finished (Welsh, 1981; Grafarend, 1979, 1984; Sahin, 1992; Yavuz, 2000).

\section{c. Estimation of variance components by MINQUE (Model 3)}

This method developed by Rao can be summarised as

$$
\sigma=\left(\sigma_{1}^{2}, \sigma_{2}^{2}, \ldots ., \sigma_{\mathrm{m}}^{2}\right)^{\mathrm{T}}=[S]^{-1} q
$$

The variance components are estimated iteratively by MINQUE method. By this method, the determination of the components can be summarised in the following steps.

Step 1. Approximate variances of observation groups $\left(\sigma_{1}^{2(0)}, \sigma_{2}^{2(0)}, \ldots . ., \sigma_{m}^{2(0)}\right)$ are selected. Then the corresponding $n \times n$ matrices $T_{i}(i=1,2, \ldots \ldots, m)$ are formed: 


$$
T_{i}=\left[\begin{array}{ccc}
0 & \cdots & 0 \\
\vdots & I & \vdots \\
0 & \cdots & 0
\end{array}\right] . \quad I: \text { Identity matrix }
$$

Step 2. Quadratic matrix $\mathrm{R}$ is formed using the equations (2.18) and (2.19):

$$
\begin{aligned}
& C_{I}=\sum_{i=1}^{m} \sigma_{i}^{2} T_{i}, \\
& R(\sigma)=\left(C_{l}\right)^{-1}\left[I-A\left[A^{T}\left(C_{l}\right)^{-1} A\right]^{-1} A^{T}\left(C_{l}\right)^{-1}\right],
\end{aligned}
$$

where $C_{l}$-covariance matrix, $R(\sigma)$ - quadratic matrix.

If the adjusted net is a free network, matrix $\left[A^{T}\left(C_{l}\right)^{-1} A\right]^{-1}$ is singular and a generalised inverse is to be used.

Step 3. In this step, the elements of matrix $S\left(S_{i j}\right)$ and matrix $q\left(q_{i}\right)$ are computed:

$$
\begin{aligned}
& S_{i j}=\operatorname{Tr}\left[R(\sigma) T_{i} R(\sigma)\right], \\
& q_{i}=l^{T} R(\sigma) T_{i} R(\sigma) l .
\end{aligned}
$$

Step 4. In this step, MINQUE equation (2.18) is solved and the variance of each group is obtained. Then the weights of the observation groups are computed using the equation

$$
P_{i+1}=\frac{P_{i}}{\sigma}
$$

If $\sigma$ is not equal to 1 , for all $\mathrm{i}=1,2, \ldots, m$ the procedure returns to step 2. When $\sigma=1$ for all observation groups, the iteration is finished (Yavuz, 2000).

\section{d. Estimation of variance components using AUE (Almost Unbiased Estimation) (Model 4)}

This method has been developed by Horn and Lucas (Lucas, 1985). It is to be applied in iterations. The brief of the method is as follows:

$$
\begin{aligned}
& \sigma=S^{-1} q, \\
& \sigma=\left(\sigma_{1}^{2}, \sigma_{2}^{2}, \ldots . ., \sigma_{m}^{2}\right)^{T}, \\
& S=\operatorname{Tr}\left(W H_{i} W H_{j}\right) \quad i, j=1,2, \ldots \ldots ., m, \\
& q=l^{T} W H_{i} W l \quad i, j=1,2, \ldots \ldots ., m .
\end{aligned}
$$

These equations are equivalent to MINQUE (Minimum Norm Quadratic unbiased Estimation) equations (Lucas, 1985). At the point of convergence, variances of the observation groups

$$
\sigma=(1,1, \ldots, 1)^{T}
$$

then equation (2.24) becomes

$$
\sigma_{i}^{2}=\frac{l^{T} W H_{i} W l}{\operatorname{Tr}\left(W H_{i}\right)} .
$$

Equation (2.27) is AUE equation for estimating the variance components concerning the observation groups, where

$$
\begin{aligned}
& W=P-P A N^{-1} A^{T} P, \\
& H_{i}=\left[\begin{array}{ccc}
0 & \cdots & 0 \\
\vdots & P_{i}^{-1} & \vdots \\
0 & \cdots & 0
\end{array}\right] .
\end{aligned}
$$

In this method, variance components are estimated by grouping the observations according to a definite criterion. The method is to be applied in iterations (Lucas, 1985; Yavuz, 2000). A priori weights can be select as $P_{1}^{(0)}=P_{2}^{(0)}=\ldots \ldots . .=P_{i}^{(0)}=1$ for all groups (Yavuz, 2000). After every iteration, the weights of the observation groups are computed by the equation

$$
P_{i+1}=\frac{P_{i}}{\sigma}
$$

When $\sigma_{i}^{2}=1$ for all observation groups, the iteration is finished (Grafarend, 1984).

In the iterative estimation of variance components, one or more of variance components can be negative during any iteration. Inexact grouping of observations can be the reason of this issue (Lucas, 1985). In the situation of getting negative estimations, the groups concerning the observations must be rearranged. If observation groups will be not rearranged, zero or very small positive numbers can be taken alternatively instead of negative estimations (Lucas, 1985).

\section{e. Estimation of variance components using the equation given by Förstner (Model 5)}

The equation by Förstner for estimating the variance components:

$$
\sigma_{i}^{2}=\frac{v_{i}^{T} P_{i} v_{i}}{z_{i}},
$$

where

$$
z_{i}=k_{i}-\operatorname{Tr}\left(P_{i} A_{i} N^{-1} A_{i}^{T}\right) \quad i=1,2, \ldots \ldots, m,
$$




$$
\begin{aligned}
& N_{i}=A_{i}^{T} P_{i} A_{i}, \\
& N=A^{T} P A, \\
& x=N^{-1}\left(A^{T} P l\right), \\
& v_{i}=A_{i} x-l_{i} .
\end{aligned}
$$

After grouping the observations according to definite criteria, the a priori weights of the groups are estimated. The solution is also performed iteratively by this method. Initial weights can be selected as

$$
P_{1}^{(0)}=P_{2}^{(0)}=\ldots \ldots . .=P_{i}^{(0)}=1
$$

for all groups. After every iteration, the group weights are computed as in equation (2.29). When $\sigma_{i}^{2}=1$ for all groups, the iteration is finished.

\section{Criterion for comparing the stochastic models}

In order to compare the stochastic models, criteria have to be defined. Resulting time, Global test (stochastic model test) on the a posterior variance factor and gross error localisation and elimination, homogeneity and isotropy with mean accuracy tests can be used for the comparison of stochastic models (Yavuz, 2000).

\subsection{Resulting time}

Observations vector and functional model are kept fixed in the adjustment computations concerning the comparison of the stochastic models. Naturally, the stochastic models, which give meaningful and true results in a practically acceptable time, are superior than the others, which do not give such results in a practically acceptable time, in computations performed by changing the stochastic model.

\subsection{Global test and gross error localisation and elimination}

In order to test the compatibility of the estimated posterior variance factor $\hat{\sigma}_{0}^{2}$ with an a priori selected variance factor $\sigma_{0}^{2}$, the global test must be applied first. In this test, $\sigma_{0}^{2}$ is compared to $\hat{\sigma}_{0}^{2}$. Under the null hypothesis $\left(H_{0}\right)$,

$$
E\left\{\hat{\sigma}_{0}^{2} \mid H_{0}\right\}=\sigma_{0}^{2}
$$

or

$$
E\left\{\left(\hat{s}_{0}^{2} / s_{0}^{2}\right) \mid H_{0}\right\}=1 .
$$

Test statistic value

$$
T=\hat{\sigma}_{0}^{2} / \sigma_{0}^{2} \ldots, \ldots \sigma_{0}^{2}>\sigma_{0}^{2}
$$

or

$$
T=\sigma_{0}^{2} / \hat{\sigma}_{0}^{2} \ldots, \ldots \sigma_{0}^{2}>\hat{\sigma}_{0}^{2}
$$

is compared with the value $\left(F_{f_{1, f}, 1-\alpha}\right.$ or $F_{f_{2}, f_{1}, 1-\alpha}$ ) taken from $F$ distribution table, where $f_{1}$ : degrees of freedom $\hat{\sigma}_{0}^{2}, f_{2}$ : degrees of freedom $\sigma_{0}^{2}, 1-\alpha$ : confidence limit. If

$$
\begin{gathered}
T>F_{f_{1, f}, 1-\alpha} \ldots . . . . \hat{\sigma}_{0}^{2}>\sigma_{0}^{2}, \\
T>F_{f_{2,1}, 1-\alpha} \ldots . . . . \sigma_{0}^{2}>\hat{\sigma}_{0}^{2},
\end{gathered}
$$

there is a model error; in other words, weights of observations are not chosen properly and zero hypothesis is rejected.

If the global test failed and some residuals show an excessive magnitude, gross error localisation and elimination technique (Baarda's data snooping or Pope tau-test) is employed.

Test statistic values for the techniques mentioned above are as follows:

Baarda (data snooping)

$$
T_{i, B}=V_{i} / \sigma_{0} \sqrt{q_{v_{i} v_{i}}} \sim N(0,1)
$$

Pope (tau-test)

$$
T_{i, P}=V_{i} / \hat{\sigma}_{0} \sqrt{q_{v_{i} v_{i}}} \sim \tau_{f}
$$

where $q_{v_{i} v_{i}}$ is weight coefficient for residual $V_{i}$.

If the test magnitudes exceed the limits below, it is accepted that gross error exists in the related observation data. In this case, this observation can be eliminated, and a new adjustment is made:

$$
\begin{aligned}
& T_{\max , B}>k_{1-\alpha_{0} / 2}=\sqrt{F_{1, \infty, 1-\alpha_{0}}}, \\
& T_{\max , P}>t_{f, 1-\alpha_{0} / 2},
\end{aligned}
$$

where $k_{1-\alpha_{0} / 2}:$ confidence limit taken from standard normal distribution table, $\tau_{f, 1-\alpha_{0} / 2}$ : confidence limit taken from $\tau$ distribution table.

After the tests, considering the condition that minimum number of the observations, which have a gross error, has been eliminated during adjustment, the stochastic model which proves null hypothesis in eq (3.2) is accepted superior than the other which rejects the null hypothesis. 


\subsection{Homogeneity test}

Homogeneity of a net depends on the convenience of the stochastic model under the condition that the other parameters of the adjustment are fixed.

In this study, the simple arithmetical mean and the standard deviation of the sum of the long (a) and the short (b) half-axis of the computed error ellipses, related to the net points after the adjustment, have been taken as a criterion to determine the superior model from the point of homogeneity.

At the end of the adjustment of a horizontal control net using any stochastic model, let the long and the short half-axis of error ellipses be related to points of $u$ numbered. Homogeneity condition for this net:

$$
\begin{aligned}
& a_{i}=a_{j}, \quad i=1,2, \ldots, u-1, \quad i \neq j, \\
& b_{i}=b_{j}, \quad j=2,3, \ldots ., u
\end{aligned}
$$

or

$$
a_{i}+b_{i}=a_{j}+b_{j}
$$

Eq (3.10) can be used for comparing the adjustment results, which have been obtained by stochastic models, from the point of homogeneity. Sum of $c_{i}=a_{i}+b_{i} \quad(i=1,2, \ldots ., u)$ concerning with each stochastic models are accepted as a measurement set. The mean values and the deviations of these measurement set

$$
c_{0}=\frac{\sum_{i=1}^{u} c_{i}}{u}, \quad \sigma^{(0)}=\sqrt{\frac{\sum_{i=1}^{u}\left(c_{0}-c_{i}\right)^{2}}{u(u-1)}} .
$$

If homogeneity condition (eq 3.10) is exactly valid

$$
c_{0}=c_{i} \text { ve } \sigma^{(0)}=0
$$

then the standard deviations $\sigma^{(0)}$ calculated from eq (3.11) are homogeneity criteria for the stochastic models. In homogeneity test, $\sigma^{(0)}$ standard deviations related to each stochastic models are compared in doubles.

$$
\text { If } \sigma_{j}^{(0)} \text { and } \sigma_{k}^{(0)} \text { are standard deviations which }
$$

belong to $j$-th and $k$-th stochastic models and the number of total stochastic model is $m$, null hypothesis

$$
\begin{aligned}
& H_{0}\left\{E\left(\sigma_{j}^{(0) 2}-\sigma_{k}^{(0) 2}\right)\right\}=0, \\
& j=1, \ldots ., m-1 ; k=2, \ldots ., m, j \neq k .
\end{aligned}
$$

and the test statistic

$$
T_{j, k}=\frac{\sigma_{j}^{(0) 2}}{\sigma_{k}^{(0) 2}}, \quad \sigma_{j}^{(0)}>\sigma_{k}^{(0)} .
$$

If

$$
T_{j, k} \leq F_{1-\alpha, f_{j}, f_{k}},
$$

null hypothesis is true. In this case, we cannot decide which one of two models is superior.

Where

$$
\begin{aligned}
& f_{j}=f_{k}=u-1, \\
& \text { if } \\
& T_{j, k}>F_{1-a, f_{j}, f_{k}},
\end{aligned}
$$

it is accepted that the stochastic model with the value of $\sigma_{k}$ is superior to the model having the value $\sigma_{j}$.

If null hypothesis is true, we cannot give decide the model superiority. In this case, mean accuracy test is applied and the superiority order of the stochastic models is made according to mean accuracy test result.

Null hypothesis for mean accuracy test,

$$
\begin{array}{cc}
H_{0}\left\{E\left(c_{0, j}\right)=E\left(c_{0, k}\right)\right\}, & j=1,2, \ldots . ., m-1 \\
k=1,2, \ldots . ., m & j \neq k
\end{array}
$$

and the test statistic,

$$
t_{j, k}=\frac{c_{0, j}-c_{0, k}}{\sqrt{\sigma_{j}^{(0) 2}+\sigma_{k}^{(0) 2}}}, \quad c_{0, j}>c_{0, k}
$$

Test value is compared with the value of $F_{1-\alpha, f}$, where

if

$$
f=2(u-1)
$$

$$
t_{j, k} \leq F_{1-\alpha, f},
$$

null hypothesis is true. In this case, it is decided that there is no superiority between two stochastic models taken.

$$
\text { If }
$$

$$
t_{j, k}>F_{1-\alpha, f},
$$

it is accepted that the stochastic model $c_{0, k}$ is superior (look eq 3.17). 


\subsection{Isotropy test}

Isotropy is a characteristic of the accuracy criteria, which are related to the positions of the points, being independent of the direction in horizontal control networks. Error ellipses take the form of circle in full isotrop nets. Mathematical form of this speciality is

$$
\begin{aligned}
& a_{i}=b_{i}, \\
& \text { or } \quad i=1,2, \ldots, u .
\end{aligned}
$$

Eq (3.20) can be used to compare the results of the adjustments, which have been obtained from the stochastic models, from the point of isotropy. In order to carry out this, the following equation belonging to each stochastic models is thought as a measurement set:

$$
e_{i}=a_{i}-b_{i} \quad(i=1,2, \ldots, u) .
$$

Then, the mean values and the standard deviations of these measurement sets are computed:

$$
\begin{aligned}
& e_{0}=\frac{\sum_{i=1}^{u} e_{i}}{u}, \\
& \bar{\sigma}=\sqrt{\frac{\sum_{i=1}^{u}\left(e_{0}-e_{i}\right)^{2}}{u(u-1)} .}
\end{aligned}
$$

These values are accepted as isotropy criteria for the comparison of stochastic models. Comparison is made similarly as in section 3.3 using the equations from (3.12) to (3.15) or eq (3.19), if needed. But in the equations mentioned above, instead of $\sigma^{(0)}$ and $\bar{\sigma}, c_{0}$ and $e_{0}$ must be used.

\section{Experiments}

In this study, the part of Istanbul Metropolitan Triangulation Network (Asiatic side of Istanbul), which was surveyed in 1987, has been selected as an application network. In order to compare the models used in this study, the net is adjusted by the least square adjustment with the free adjustment approach by the stochastic models. After testing the adjustment results, the stochastic models, selected for this study, has been compared using some criteria mentioned in section 3, proposed by Yavuz, (2000).

The observations have to be divided into groups and the weights have to be determined iteratively according to model 2, 3, 4, 5 .

448 direction and 208 distance observations were made in the net. Because of a detailed information, which will form the base for grouping the measurements, like types of instruments used during surveying, which directions and distances were measured by using these instruments, date of measurements has not been obtained, observations have been separated into two groups like a group formed by using directions, another group formed by using distances for model 2, 3, 4, 5 .

In free net adjustment formed by using model 1 , a priori standard deviation of unit weighted observations has been selected as $\sigma_{0}= \pm 0,1136^{\mathrm{mgon}}$ which was computed from station adjustment made for a station point. All computations have been made by a personel computer which has the properties like Pentium $4 \mathrm{CPU}$, 512MB RAM.

\subsection{Comparison of the models according to criterion 1}

The needed time for determining the observation weights has been taken as criterion 1 . It continued $<1$ min for model 1. For other models, which need iteration, the needed time is as follows :

$\begin{array}{ll}\text { Model 2 } & 1^{m} 22^{s} \\ \text { Model 3 } & 32^{m} 15^{s} \\ \text { Model 4 } & 16^{m} 20^{s} \\ \text { Model 5 } & 6^{m} 20^{s}\end{array}$

Iteration numbers concerning the determination of the variance components (observation weights) and total times are given in Table 1.

Table 1. Total iteration times to calculate the weights of the models according to two observation groups $\sigma^{2}=1$ for all models)

\begin{tabular}{|c|c|c|c|c|}
\hline $\begin{array}{c}\text { Model } \\
\text { No }\end{array}$ & $\begin{array}{c}\text { Total } \\
\text { iteration } \\
\text { number }\end{array}$ & Total time & \multicolumn{2}{|c|}{ Calculated weights } \\
\cline { 4 - 5 } & 7 & $0^{\mathrm{h}} 9^{\mathrm{m}} 34^{\mathrm{s}}$ & 0,2575835929 & 0,1689553333 \\
\hline $\begin{array}{c}\text { Model } \\
2\end{array}$ & 7 & $3^{\mathrm{h}} 45^{\mathrm{m}} 45^{\mathrm{s}}$ & 0,2575839782 & 0,1689548039 \\
\hline $\begin{array}{c}\text { Model } \\
3\end{array}$ & 7 & $2^{\mathrm{h}} 43^{\mathrm{m}} 20^{\mathrm{s}}$ & 0,2575828403 & 0,1689563675 \\
\hline $\begin{array}{c}\text { Model } \\
4\end{array}$ & 10 & $1^{\mathrm{h}} 09^{\mathrm{m}} 40^{\mathrm{s}}$ & 0,2575834582 & 0,1689555168 \\
\hline $\begin{array}{c}\text { Model } \\
5\end{array}$ & 11 & \\
\hline
\end{tabular}

The final adjustment computation step has been finished in $4 \mathrm{~min}$ for both models. As a result, considering the total computation times, the superiority arrangement of the models according to criterion 1 can be given as
1. Model 1
$\sim 5^{m}$
2. Model 2
$0^{h} 13^{m} 34^{s}$
3. Model 3
$1^{h} 13^{m} 40^{s}$
4. Model 4
$2^{h} 47^{m} 20^{s}$
5. Model 5
$3^{h} 49^{m} 45^{s}$ 


\subsection{Comparison of the models according to criterion 2}

Global test (stochastic model test) for a posterior variance factor has been applied to the adjustment results, which have been obtained by the adjustment of Asiatic site of Istanbul. Using all measurements (448 directions and 208 distances), the fallowing results have been obtained (comparison value taken from $F$ distribution table $F_{431, \infty, 0,95}=1,172$ );

For model 1

$$
T=\frac{1,848^{2}}{1,136^{2}}=2,646>1,172
$$

null hypothesis is rejected.

$$
\text { For model } 2,3,4,5 \quad T=\frac{1,084^{2}}{1^{2}}=1,175>1,172
$$

null hypothesis is rejected.

Because the null hypothesis is rejected in all models, gross error detection (localisation and elimination) tests have been applied and the results obtained (Table 2).

Table 2. Gross error detection test results obtained by the free adjustment of Asiatic side of Istanbul using all observations

\begin{tabular}{|l|c|c|}
\hline \multicolumn{2}{|c|}{ Gross error detection test } \\
\hline & $\begin{array}{c}\text { Direction } \\
\text { observations with } \\
\text { gross error }\end{array}$ & $\begin{array}{c}\text { Distance } \\
\text { observations with } \\
\text { gross error }\end{array}$ \\
\hline $\begin{array}{l}\text { Model 1 } \\
\text { Baarda-Data } \\
\text { Snooping }\end{array}$ & 22 directions & 6 distances \\
\hline $\begin{array}{l}\text { Model 2, 3, 4, 5 } \\
\text { Pope Tau and } \\
\text { Baarda-Data } \\
\text { Snooping }\end{array}$ & 3 directions & 1 distance \\
\hline
\end{tabular}

After the elimination of 4 observations with gross error (Table 2) from the observation set, the adjustment has been remade using all the models and the global test (stochastic model test) on the a posterior variance factor has been reapplied to the adjustment results (comparison value taken from $F$ distribution table $\left.F_{425, \infty, 0.95}=1,173\right)$.

$$
\text { For model } 1 \quad T=\frac{1,568^{2}}{1,136^{2}}=2,460>1,173 \text { null }
$$

hypothesis is rejected.

$$
\text { For model 2, 3, 4, } 5 T=\frac{1^{2}}{0,941^{2}}=1,129<1,173 \text { null }
$$

hypothesis is true.

The results mentioned above prove that a lot of measurements must be eliminated from the observations heap for model 1 . But, because of the elimination of 28 observations with gross error (Table 2) might weak the net geometry, this has not been done. As a result, the superiority arrangement of the models according to criterion 2 can be given as
1. Model 2, 3, 4, 5

5. Model 1

\subsection{Comparison of the models according to criterion 3}

Homogeneity test (criterion 3) (for further information look Yavuz, 2000) results are in Table 3.

Table 3. Homogeneity and mean accuracy test results applied to the adjustment results obtained by adjusting Asiatic side of Istanbul net

$$
F_{75,75,0.95}=1,4656, \quad F_{150,0.95}=1,6551 \text {. }
$$

\begin{tabular}{|c|c|c|c|c|c|}
\hline $\begin{array}{c}\text { Model } \\
\text { No }\end{array}$ & $\begin{array}{c}\mathbf{1} \\
\sigma^{(0)}=\end{array}$ & $\begin{array}{c}\mathbf{2 , 3 , 4 , 5} \\
\sigma^{(0)}= \\
0,0939\end{array}$ & $\begin{array}{c}\text { Superior } \\
\text { model } \\
\text { according to } \\
\text { homogeneity }\end{array}$ & $\begin{array}{c}\text { Mean } \\
\text { accuracy } \\
\text { test } \\
\text { value }\end{array}$ & $\begin{array}{c}\text { Superior } \\
\text { model } \\
\text { according } \\
\text { to mean } \\
\text { accuracy }\end{array}$ \\
\hline 1 & & $T=1,8573$ & $2,3,4,5$ & & \\
\hline
\end{tabular}

Because the models are equivalent besides model 1 and they are superior than model 1 (Table 3 ), superiority arrangement of the models according to criterion 3 can be given as

1. Model 2, 3, 4, 5

5. Model 1

\subsection{Comparison of the models according to criterion 4}

Isotropy test (criterion 4) (for further information look Yavuz, (2000) results have been given in Table 4.

\begin{tabular}{|c|c|c|c|c|c|}
\hline $\begin{array}{c}\text { Model } \\
\text { No }\end{array}$ & $\begin{array}{c}1 \\
\bar{\sigma}= \\
0,0184\end{array}$ & $\begin{array}{c}2,3,4,5 \\
\bar{\sigma}= \\
0,0156\end{array}$ & $\begin{array}{l}\text { Superior } \\
\text { model } \\
\text { according } \\
\text { to isotropy }\end{array}$ & $\begin{array}{c}\text { Mean } \\
\text { accuracy } \\
\text { test value }\end{array}$ & $\begin{array}{c}\text { Superior } \\
\text { model } \\
\text { according } \\
\text { to mean } \\
\text { accuracy }\end{array}$ \\
\hline 1 & & $T=1,3912$ & equivalent & $t=1,5298$ & equivalent \\
\hline
\end{tabular}

Table 4. Homogeneity and mean accuracy test results applied to the adjustment results obtained by adjusting Asiatic side of Istanbul net

$$
\mathrm{F}_{75,75,0,95}=1,4656, \quad \mathrm{~F}_{150,0,95}=1,6551 \text {. }
$$

As a result, the superiority arrangement of the models according to criterion 4 can be given as

1. Model 2, 3, 4, 5

5. Model 1

4.5. The evaluation of the results related to the adjustment of Asiatic side of Istanbul net considering the whole criterion

The general superiority arrangement of the models, according to the whole criterion in the adjustment of Asiatic side of Istanbul net, are summarised. 
Table 5. General superiority arrangement of the models

\begin{tabular}{|c|c|c|c|c|c|c|}
\hline $\begin{array}{c}\text { Model } \\
\text { No }\end{array}$ & $\begin{array}{c}\text { Criter } \\
\mathbf{1}\end{array}$ & $\begin{array}{c}\text { Criter } \\
\mathbf{2}\end{array}$ & $\begin{array}{c}\text { Criter } \\
\mathbf{3}\end{array}$ & $\begin{array}{c}\text { Criter } \\
\mathbf{4}\end{array}$ & Total & $\begin{array}{c}\text { General } \\
\text { arrangment }\end{array}$ \\
\hline $\mathbf{1}$ & 1 & 5 & 5 & 5 & 16 & 5 \\
\hline $\mathbf{2}$ & 2 & 1 & 1 & 1 & 5 & 1 \\
\hline $\mathbf{3}$ & 5 & 1 & 1 & 1 & 8 & 4 \\
\hline $\mathbf{4}$ & 4 & 1 & 1 & 1 & 7 & 3 \\
\hline $\mathbf{5}$ & 3 & 1 & 1 & 1 & 6 & 2 \\
\hline
\end{tabular}

According to Table 5, the models except for model 1, are equivalent to 3 criterions. Only calculation times are different.

\section{Conclusion}

The stochastic models determined by the methods like Helmert, Minque, AUE, Förstner, etc have to be used instead of the conventional stochastic model determination, especially in the adjustment of geodetic nets, which require accuracy and precision. These methods, besides conventional method, are already widely used in the developed countries. Beside theoretical manner, the importance of these models has not been taken into consideration in turkey until now. These models, which have proved the superiorities over the conventional model by the aid of theoretical research and practical applications, which have been done in this study, must be used in private and public sector surveying applications.

\section{References}

Grafarend, E. W.; Schaffrin, B. Variance-Covariance Component Estimation of Helmert Type. Surveying and Mapping, XXXIX, 1979, p. 225-234.

Grafarend, E. W. Variance-Covariance Component Estimation of Helmert Type in the Gauss-Helmert Model, ZFV, 1, 1984, p. 34-44.

Lucas, J. R. A Variance Component Estimation Method for Sparse Matrix Applications. NOAA Technical Report NOS 111 NGS 33, 1985.
Sahin, M.; Cross, P. A.; Sellers, P. C. Variance Component Estimation Applied to Satellite Laser Ranging. Bull. Geod., 66, 1992, p. 284-295.

Welsh, W. Estimation of Variance and Covariance of Geodetic Observations. Aust. J. Geod. Photo. Surv., 34, 1981, p. 1-14.

Yavuz, E. Stochastic Model Research in Horizontal Control Networks. PhD thesis, ITÜ, 2000 (in Turkish).

Erol Yavuz. Doctor. Yildiz Teknik Universitesi Meslek Yuksekokulu Buyukdere Caddesi No: 69 Maslak, SisliIstanbul, Turkey $(\mathrm{Ph}+9021228692$ 23,

Fax +90 21227668 88),

e-mail: erolyavuz1962@hotmail.com.

Author of 3 books and more than 10 scientific papers.

Research interests: surveying, engineering surveys, computer and development of professional softwares, tunnelling, standardisation in surveying.

Orhan Baykal. Professor, Doctor. Istanbul Teknik Universitesi Insaat Fakultesi Jeodezi ve Fotogrametri Bolumu, 34469 Maslak, Sisli-Istanbul, Turkey

(Ph +90 2122853782 (6587), Fax +90 21228537 82),

e-mail: obaykal@srv.ins.itu.edu.tr.

Author of 2 books and more than 50 scientific papers.

Research interests: geometrical route designing in transportation structure, deformation measurements, engineering surveys, surveying.

\section{KINTAMOSIOS KOMPONENTĖS VERTINIMO METODŲ PALYGINIMO IŠLYGINANT HORIZONTALIUOSIUS TINKLUS KRITERIJAI}

\section{E. Yavuz, O. Baykal}

Analizuojama, kuris stochastinis metodas tinkamesnis horizontaliesiems tinklams apdoroti esant tam tikroms sąlygoms. Palyginama keletas stochastinių metodų - iprastinis, Helmerto, MINQUE, AUE ir Forstnerio, kurie taikomi geodeziniams tinklams išlyginti praktikoje. Statistiniais testais nustatyti sprendimu kriterijai, pagal kuriuos palyginta taikytu metodų pranašumai. Taip pat pateikiami skaičiavimų su Stambulo trianguliacijos tinklo duomenimis rezultatai.

Prasminiai žodžiai: horizontalusis tinklas, kintamosios komponentès vertinimo metodas, geodezinio tinklo išlyginimas. 